time, is fully a ninth magnitude, and will be found even with the Berlin chart for Hour 23 of R.A., which is by no means one of the most complete of the series. Metis is another member of this group of planets, at present easily recognised.

D'ARREST'S COMET. - M. Leveau is continuing his researches on the motion of this interesting comet, and has obtained elements which represent with considerable precision the observations in $1851,1857-58$, and 1870 ; allowance being made for the difficulty of fixing the place of so faint and diffused an object, and for the magnitude of the perturbations due to the action of the planet Jupiter ; these perturbations are found to have changed the R.A. of the comet on September 24,1870 , by $-14^{\circ} .6$, and the declination by $+7^{\circ} \cdot 6$. M. Leveau has employed Bessel's mass for Jupiter, and concludes that it is susceptible only of very small correction. He promises, in a future communication to the Paris Academy of Sciences, to furnish an ephemeris for the next return of the comet to perihelion in the spring of 1877 .

\section{ON THE OCCURRENCE IN NEW ҰERSEY OF SUPPOSED FLINT SCALPING-KNIVES}

$T \mathrm{~N}$ glancing over a considerable series of American stone implements, we quite naturally expect to find that everpresent feature of the modern Indian's outfit, the scalpingknife. In every collection we recognise the stone axe that preceded the iron tomahawk; the jasper arrow and spear heads, now replaced by metallic ones; while neatly edged flints of various she.pes give us cutting implements adapted to all ordinary uses; but not so with the scalping-knife. However large the series, we cannot, at a glance, point out a form of knife peculiarly well adapted for such a purpose, from the several shapes before us. While all are possible scalping-knives, none probably are so. This, at least, has been my experience until very lately, although I have constantly sought out "probable scalping-knives" from thousands of implements gathered and being gathered in this neighbourhood. Among the hundreds of specimens of flint knives there occurred none that resembled the modern knife, and I supposed that the stone scalpers were similar-the later being modelled from earlier form.

Whether the above inference is correct or not, I have at last detected some specimens that more nearly approach the "ideal form," one such being the flint implement here figured. The result of my collecting labours during the past summer amounts to about five hundred specimens not including fragments, and it is among these that I found the cutting implement above mentioned, with several others like it, both perfect and fragmentary. As the illustration shows, better than any description can do, this slightly curved knife seems moderately well adapted for scalping, as described by Loskiel.* He says : "They place their foot on the neck of the victim, seizing the hair with the left hand, and twisting it very tight together, in order to separate the skin from the head; then they cut it all round with a sharp knife, and tear it off." The specimen is a neatly chipped and evenly outlined jasper "implement," having the edges still well defined and sharp. The curved, and I presume cutting edge, is formed by striking off comparatively large flakes, and is better adapted to making a "clean" cut, than the straighter side. The lower end, about one-fourth of the whole length, is somewhat narrower, and while less sharp along its edges, is thinner, and has no median ridge. This portion, very possibly, was inserted into a bone handle as modern Eskimo scrapers now are (vide "Reliquiæe Aquitan." Part ii. p. 14); and if so, we surely have, in the figured implement, one that would conveniently serve as a scalping-knife. In the interest of archæology

* Mission among North American Indians. London, r794; P. I49.
I should like to experiment with this specimen, but have no available scalp at hand; my own, unfortunately, being quite innocent of hair.

There being no mineral found near here that gives off Iong thin flakes like true flint or Mexican obsidian, which latter was used for razors by the Mexican Indians, and the shells of our Delaware River unios being too thin and small to serve such a purpose, we must fall back on the jasper and quartz pebbles of the neighbourhood for the material for such knives.

The number of scalping-knives in use at all times must have been considerable, and this fact alone seems counter to my suggestion that the specimen figured may be a scalping-knife, inasmuch as so very few knives of this pattern have been found here. It must be remembered, however, that every warrior would have his knife buried with him, if not killed in battle, when the knife would be lost or stolen; and one such knife would last a lifetime, so that here may be an explanation of their comparative

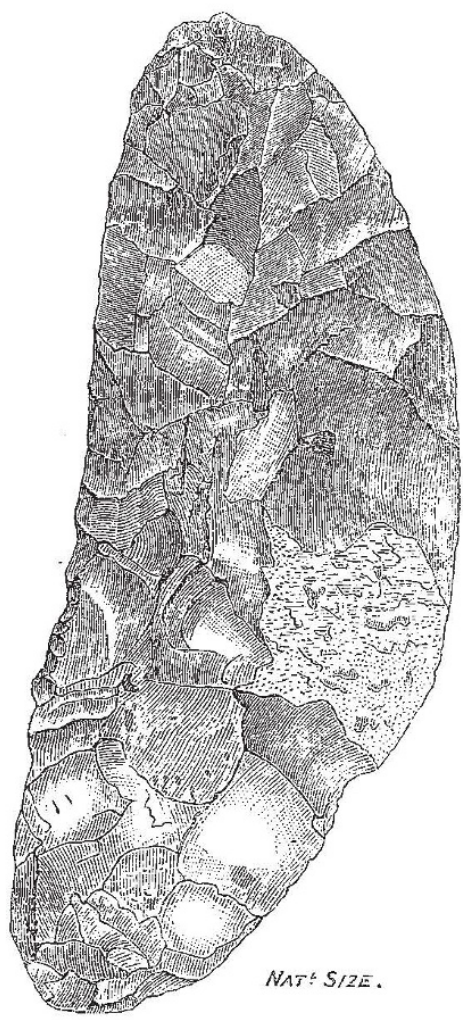

rarity, the great mass of them still lying in the nearly obliterated graves. Or, like smoking pipes, they may have been handed down from one generation to another, their peculiar use rendering them sacred in the eyes of the savage; and when buried with the other "personal effects " of the dead warrior, like the buried pipes, they may have been exhumed by those too lazy to make or too poor to purchase for themselves. That graves were thus robbed is certainly true.

In the graves that I have been fortunate enough to examine I have found cutting implements of jasper, quartz, and slate; and, twice, jasper specimens like the above. These graves to which I refer are now only to be detected by the presence of such imperishable relics as stone implements, pottery, and by the discoloration of the soil. Judging from appearances, the body was placed at full length on the surface of the ground, the weapons placed with it being grouped together on the right side, and a vase of rude pottery filled with a red powder at the 
feet. The body was then probably covered with bark, or skins of animals. Of course the decomposition would go on very rapidiy, and soon no trace remain except the bones and stone implements; then the weapons only. My reason for believing these graves to be "surface" burials is in consideraiion of the fact that the inhumed weapons and discoloured dirt are only from three to six inches beneath the sod, and this accumulation of soil is that arising from the annual decay of the preceding summer's foliage, coupled with the dust that would naturally gather around any object lying on the ground. The graves such as I have described, too, are only to be found on the slopes of grassy hill-sides that as yet have not been disturbed by the plough. I have never seen such a grave in a ploughed field. Such have been long obliterated; and the relics now found in fields may or may not be those that were buried with their prehistoric owners.

In conclusion, then, seeing that the custom of scalping was not introduced with a knowledge of metals, but preceded it, it is certain that some stone implement was used; and if in a large series of cutting tools we find some that bear resemblance to the modern form, then it is fair to presume that these, and these principally if not wholly, were those formerly in use.

A few words concerning this custom of scalping : is it peculiarly North American? I should be much pleased to learn from some correspondent of NATURE what other races, if any, have the same practice among them. Inasmuch as the Indian custom required of every warrior incontestable proof of his success in battle or in single combat, and considering that a warrior would frequently attack singly some member of a hostile tribe (See Catlin's "North American Indians"), it seems quite a natural method of showing beyond doubt that the claimant had indeed killed his foe. To produce any portion of another's clothing, or his weapons, would not prove the enemy to have been killed; to produce his scalp shows that such was certainly the case, as the instances of survival after scalping are too few to be considered. Did the custom originate in North America, or was it brought from beyond our borders?

Trenton, New Jersey, Aug. 7

Chas. C. AвBOtT

\section{THE SLIDING SEAT FORESHADOWED}

$T$ is a curious and suggestive fact that nearly all the most ingenious and important mechanical inventions find their representatives in the human frame; consequently, the more we investigate the wonderful mechanism of man's body, the more insight may we expect to get into the principles necessary for the most perfect adaptation of means to ends. Whether we take the lever the pulley, the inclined plane, the spiral or the curved spring, the arch, or any other simple uncomplicated contrivance adapted with a view to securing strength, or motion, or elasticity, we find it represented in animai mechanics, and arranged sometimes simply, sometimes in a more complex form, in a manner and with a result far more wonderful than ever produced from the most ingenious conceptions, of man's brain.

Of late years the application of the sliding seat to rowing has attracted considerable attention, and although it is beyond the purpose of this paper to consider fully the advantages gained by its application, it will, I think, be necessary to make some reference to what appear to be its principles before we inquire whether it can be traced as existing in certain of the joints.

In the mechanics of rowing we may look upon the hips and spinal column as theoretically a firm, unyielding lever (Fig. 3, S), since it is knit together by the power of the muscles in a man thoroughly trained. The object of this fixedness is evidently to avoid the loss of power and time which would occur if parts had to be strung together preparatory to the pull as the oar catches the water. This spinal lever has its fulcrum at what we call the tuberosities of the ischia $(t)$, or in other words at the points of contact of the body with the seat, and the motive power is placed in the muscles of the back and those of the thigh. The weight to be moved will be acted upon

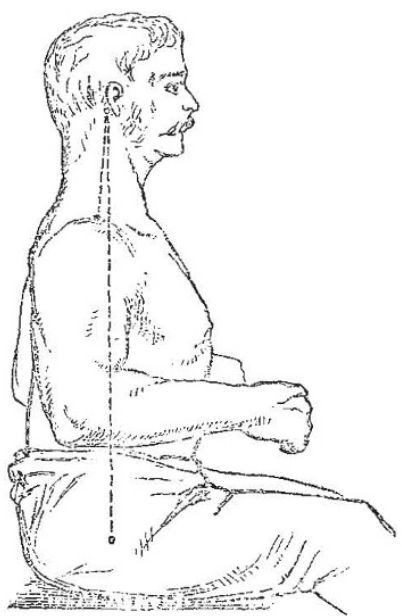

FlG. I - Sitting at rest. Showing tip of shoulder behind the line from mastoid process to hip.

through the arms at the junction of the upper extremities with the spinal lever.

As the body moves forwards, the lever formed by the spine rotates round the tuberosities which constitute the fulcrum, and which slide forward at the same time. The knees are consequently slightly bent or separated. As the oar catches the water the body is brought back to the perpendicular by the action of the muscles of the back and those of the thigh, and the lower end of the lever is at the same time carried bodily back a distance of about eight inches.

The whole principle appears to be that of a sliding fulcrum, and the peculiar result seems to be that a greater reach is given with less bending forward of the body ; for to obtain the same length of stroke the body must either be bent forward at a much more acute angle or carried back beyond the perpendicular. An increased bending

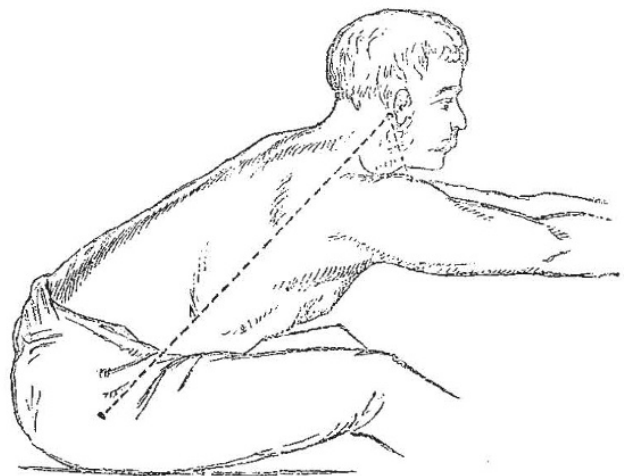

Frg. 2.-Forward movement in rowing, showing tip of shoulder far in front of the line from mastoid process to hip.

forwards, it must be borne in mind, must interfere with the respiration in a long-continued strain as in a race, and therefore with the staying powers of the individual.

If, on the other hand, the body be carried backwards beyond the perpendicular, the power of recovery is diminished, and far greater work is thrown upon the muscles of the trunk and lower limbs. 